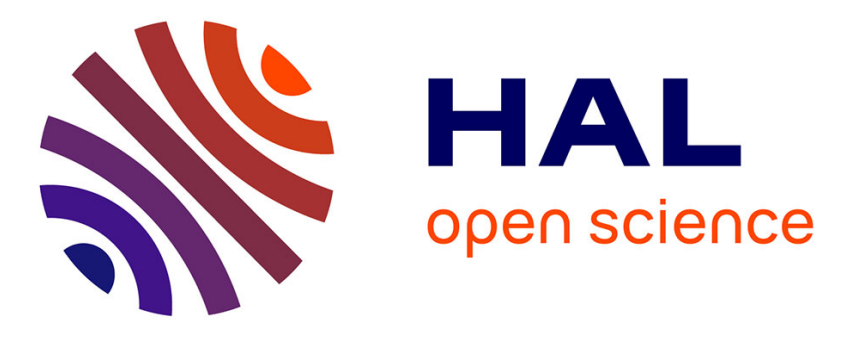

\title{
Tensile post-impact behaviour of thin carbon/epoxy and glass/epoxy hybrid woven laminates - Part II: Numerical study
}

\author{
A. Rogani, Pablo Navarro, Steven Marguet, Jean-François Ferrero, C. \\ Lanouette
}

\section{To cite this version:}

A. Rogani, Pablo Navarro, Steven Marguet, Jean-François Ferrero, C. Lanouette. Tensile post-impact behaviour of thin carbon/epoxy and glass/epoxy hybrid woven laminates - Part II: Numerical study. Composite Structures, 2019, 230, pp.111455. 10.1016/j.compstruct.2019.111455 . hal-02305928

\section{HAL Id: hal-02305928 \\ https://hal.science/hal-02305928}

Submitted on 9 Oct 2019

HAL is a multi-disciplinary open access archive for the deposit and dissemination of scientific research documents, whether they are published or not. The documents may come from teaching and research institutions in France or abroad, or from public or private research centers.
L'archive ouverte pluridisciplinaire HAL, est destinée au dépôt et à la diffusion de documents scientifiques de niveau recherche, publiés ou non, émanant des établissements d'enseignement et de recherche français ou étrangers, des laboratoires publics ou privés. 


\title{
Tensile post-impact behaviour of thin carbon/epoxy and glass/epoxy hybrid woven laminates - Part II : numerical study
}

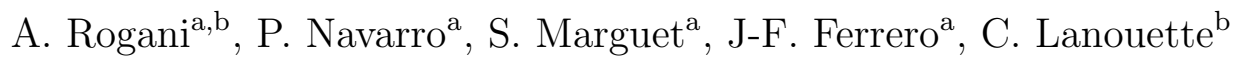 \\ ${ }^{a}$ Université de Toulouse, Institut Clément Ader, UMR CNRS 5312, \\ UPS/INSA/ISAE/Mines Albi, 3 rue Caroline Aigle, 31400 Toulouse, France \\ ${ }^{b}$ Airbus Helicopters, 1 Place du Générale Valérie André, 93440, Dugny, France
}

\begin{abstract}
This article concerns the modelling of post-impact damage propagation in thin woven composite laminates. Simulations of low velocity impacts and post-impact quasi-static tension are performed on single-material and hybrid laminates. The modelling is based on the semi-continuous approach implemented into the explicit finite element code RADIOSS. The bundles are modelled with rod elements and a specific damageable shell element is used to stabilize this truss structure. Improvements are brought with the introduction of a compressive failure criterion for the rod elements and the development of a pseudo-plastic law with damaging for in in-plane shear. The results provided by the modelling well correlates the experimental observations in terms of damage propagation and load-displacement curves for all the configurations studied.
\end{abstract}

Keywords: Woven composites, thin laminates, hybrid laminates, post-impact behaviour, explicit F.E modeling, damage

\section{Introduction}

This article deals with the modelling of post-impact damage propagation in thin hybrid woven laminates (multiple materials and orientations) subjected to quasi-static tensile test. This paper is the second part of a two-parts article : the phenomenons which occur during the tensile test have been investigated through several experimental tests on single-material and hybrid laminates, and are described in part I. 
Concerning the modelling of the post-impact behaviour of composite laminates, most of the studies are realized on unidirectionnal carbon laminates. Moreover, as the buckling due to compression is a critic aspect in order to evaluate the toughness of a composite laminate, only the compression after impact (CAI) is studied. First, simple models, based on analytical approaches $[1,2,3]$, semi-empirical approaches $[4,5,6]$ or finite element (FE) calculations $[7,8,9,10,11]$ have been developped to estimate the residual compressive strength of the impacted laminate. They mainly use criterions based on delamination growth or buckling instability in order to evaluate the residual strength of the laminate, while [4] and [5] draw a parallel with notched laminates using the point stress failure criterion (PSFC) to predict the compressive strength of various CFRP laminates. However, these studies are not sufficient because the damage used for the CAI calculation is only implemented in the model using experimental observations (such as permanent indentation shape or stiffness degradation) and non-destructive testings. Thus, the most recent studies use models capable of predict the damage due to impact and then realize the CAI simulation to take into account the permanent indentation after impact $[12,13,14,15,16,17,18,19,20]$. Also in this case, most of the models use criterions based on delamination growth (taken into account through cohesive elements) and matrix cracking. But, some authors, who have observed during CAI tests that the presence of fiber breakage around the impact area are the reason of the final break, introduce fiber failure criterion.

Very few studies on the post-impact behaviour are conducted on woven composites laminates. The compressive post-impact behaviour is the most studied [21, 22] and the developed models try to predict the compressive strength of the impacted laminate. Yan et al. use a complex FE simulation in which the interlaminar debonding, the matrix and fibers crackings, the buckling and the interactions between these mechanisms are represented. The matrix and the fibers are modelized with an homogenized volumic element and the delamination is calculated through cohesive elements. However, the damage due to the impact is initially introduced in the model as a result of experimental observations [21]. Althought Mendes et al. develop a FE model able to simulate the impact and the CAI test. The matrix and the fibers are represented by homogenized shell elements and the interface between the plys by cohesive elements. The intralaminar and interlaminar damage propagations are calculated through criterions based on energy re- 
lease rates [22]. The simulations, respectively performed on glass/vinyl-ester and carbon/epoxy woven composite laminates are capable of reproducing experimental results with good accuracy for the impact tests and CAI tests. The flexural post-impact behaviour is studied by Papanicolaou et al. [23] who compare two different analytical model to predict the residual flexural strength after impact. Colombo et al. develop a simple model to investigate the post-impact tensile behavior of a carbon/epoxy laminate, but only to evaluate the post-impact residual stiffness [24]. A Unit Cell (UC) is developed at the microscale in which warp and weft bundles, resin between the bundles and resin in the bundles are modelled. The idea is to define a simple numerical procedure to simulate the degradationof the impacted woven by changing the mechanical properties of this UC. To do that, a range of experimental impact tests are realized to evaluate the size and type of damage and the residual stiffness corresponding. Then, to simulate the damage due to the impact, the elastic modulus of the matrix in $\mathrm{UC}$, corresponding to the impacted region, is degraded by a coefficient of reduction. Finally, a numerical analysis is ran to determine the laminate residual stiffness. It is compared with the experimental data and give good results. However, this model can not represent the damage propagation and is very depending on the experimental observations.

The objective of this study is to model quasi-static tensile tests on impacted woven laminates with the semi-continuous approach [25, 26, 27, 28]. For this purpose, the existing semi-continuous strategy has been improved. Indeed, some add-ons, based on experimental observations made in Part I, are implemented through the development of a damaging pseudo-plastic law in plane-shear and the introduction of a new criterion for the break of fibres bundles in compression. Finally, the model is validated by several simulations on the same single-material laminates (Table 1) and hybrid laminates (Table 2) used in Part I. The results are finally compared to the experiments.

\section{Extension of the semi-continuous model to tensile simulations}

\subsection{Semi-continuous model for impact simulations}

The semi-continuous model, developped in the research team for woven laminates subjected to impact loadings, has been already presented in the articles $[25,26,27,28]$. The modelling of the woven ply decouples the resin and 
tows behaviour to represent simultaneously the damaged resin and the undamaged fibers tows. A specific finite element has been developped (Figure 1) with a truss structure of rod elements, modelizing the woven fabric bundles and following the woven pattern geometry, and a shell element, placed at the neutral axis of the ply, which represent the epoxy matrix. The mesh size respects the woven fabric pattern and the nodes of the rods are offset from the shell to a distance of $h / 4$ in the thickness direction where $h$ is the thickness of the ply. The connection between the rods and the shell elements is realized at the nodes through rigid links. Finally, an interface element, with an elasting damaging behaviour and a bilinear cohesive law in order to represent the delamination, is added in order to connect two plies.

The rod element has an elastic and brittle behaviour with a maximal tensile strain criterion for its break :

$$
\text { If } \varepsilon>\varepsilon_{\max }^{\text {tension }} \text { then break of the rod element }
$$

The resin is modelized by a specific elastic and isotrop shell element for which an anisotropic damaging has been implemented for each direction of the woven throught two damage variables $d_{1}$ and $d_{2}$, based on thermodynamical functions $Y_{i}$, which came degrade shell and bending matrices :

$$
\left[C^{\text {shell }}\right]=\left[C^{\text {bend }}\right]=\left[\begin{array}{ccc}
\frac{\left(1-d_{1}\right) E_{11}}{1-\left(1-d_{1}\right)-\left(1-d_{2}\right) \nu^{2}} & \frac{\left(1-d_{1}\right)\left(1-d_{2}\right) \nu E_{11}}{1-\left(1-d_{1}\right)-\left(1-d_{2}\right) \nu^{2}} & 0 \\
\frac{\left(1-d_{1}\right)\left(1-d_{2}\right) \nu E_{22}}{1-\left(1-d_{1}\right)-\left(1-d_{2}\right) \nu^{2}} & \frac{\left(1-d_{2}\right) E_{22}}{1-\left(1-d_{1}\right)-\left(1-d_{2}\right) \nu^{2}} & 0 \\
0 & 0 & G_{12}
\end{array}\right]
$$

Concerning impact simulations, in comparison to the experimental results, the semi-continous model gives accurate results in terms of sizes and shape of damages and load curves for diverse laminates configurations (singlematerial or hybrid laminates). But, it requires some adds-on in order to correctly represent the post-impact quasi-static tensile behaviour of these laminates.

\subsection{Adds-on to the semi-continuous model}

\subsubsection{Compressive strain criterion for rod element}

The experimental testings on the hybrid laminate G0C45C45 have shown in the Part I that the elongation of the upper glass ply G0 is piloted by 
the two carbon plies at $\pm 45^{\circ}$, what generates areas of compressive strains in the glass plys due to the Poisson effect of these two carbon plies. Thus, the propagation of the post-impact damage in the glass ply is made at $\pm 45^{\circ}$ due to compressive break of fibres. So, in the modelling, it is necessary to add a compressive strain criterion for the rod element in addition to the tensile strain criterion :

$$
\text { If } \varepsilon(x)<\varepsilon_{\max }^{\operatorname{comp}} \text { then break of the bar element }
$$

The value of $\varepsilon_{\max }^{\text {comp }}$ for glass and carbon woven are chosen such as :

$$
\frac{\left|\varepsilon_{\text {max glass }}^{\text {comp }}\right|}{\varepsilon_{\text {max glass }}^{\text {tension }}}=0.48 \text { and } \frac{\left|\varepsilon_{\text {max carbon }}^{\text {comp }}\right|}{\varepsilon_{\text {max carbon }}^{\text {tension }}}=0.75
$$

What is in accordance with Eksi [29] who characterized the glass and carbon woven in tension en compression and found :

$$
\frac{\left|\sigma_{\text {max glass }}^{\text {comp }}\right|}{\sigma_{\text {max glass }}^{\text {tension }}}=0.45 \text { and } \frac{\left|\sigma_{\text {max glass }}^{\text {comp }}\right|}{\sigma_{\text {max glass }}^{\text {tension }}}=0.8
$$

Furthermore, in a woven ply, the fibres bundles located at a cross-point are in local bending. So, they need a more important tensile strain in order to spread out and reach the tensile strain criterion and on the contrary, they need a less important compressive strain to reach the compressive strain criterion. So, at a cross-point, $\varepsilon_{\max }^{\text {tension }}$ is increased and $\left|\varepsilon_{\max }^{\text {comp }}\right|$ is reduced. For this purpose, $\varepsilon_{\text {max cross }}^{\text {comp }}$ and $\varepsilon_{\text {max cross }}^{\text {tension }}$ are introduced in the model such as :

$$
\frac{\left|\varepsilon_{\text {max cross }}^{\text {comp }}\right|}{\left|\varepsilon_{\text {max }}^{\text {comp }}\right|}=\frac{\varepsilon_{\text {max }}^{\text {tension }}}{\varepsilon_{\text {max cross }}^{\text {tension }}}=0.7
$$

\subsubsection{Damaging pseudo-plastic law}

\section{Introduction.}

The experimental testings of the Part I have shown, for the hybrid configuration G0C45C45, that the two carbon plies at $\pm 45^{\circ}$ was piloting the elongation of the upper ply G0, but also the existence of areas of strain field $\varepsilon_{x y}$ with vectors of principal strain directed at $\pm 45^{\circ}$ (which are areas where 
the resin is loaded) for the single-material laminates. So, in order to represent the loading and the damaging of the resin, it is necessary to intruce in the model a damaging law in plane shear for the carbon woven.

\section{Experimental observations.}

A cyclic tensile test is performed on two plies of carbon woven oriented at $\pm 45^{\circ}$ with the same characteristics of the sample and the tensile as in the Part I. A classic load - displacement curve is obtained and presented on the Figure 2. First, from a certain value of shear stres, after the unload, the crosshead displacement does not come back to zero. Which is specific of the emergence of plastic shear strains (irreversible strains) in the laminate and means that the carbon woven has a pseudo-plastic behaviour in plane shear. The curve shows also a decrease of the shear stiffness $G_{12}$ during the test. It is driven by the emergence and the growth of damage in the laminate. In fact, during quasi-static tensile tests on carbon/epoxy woven laminate oriented at $\pm 45^{\circ},[30,31]$ observed first the initiation of cracks in areas full of resin (fibres/resin splitting) for a strain of 0.88 and then the initiation of cracks in bundles for a strain of $1.2 \%$ which propagate thereafter in metadelamination (delamination between warp and weft bundles).

The splittings quicky evolve at the beginning of the test then they stabilize athought the cracks in the bundles and the meta-delaminations slowly grow at the beginning and suddenly accelerate once the splittings no longer evolve. Finally, the meta-delaminations come dissociate the warp and the weft, what leads to their rotation and generates break of bundles at a high strain rate. The emergence of each type of damage is represented on the Figure 2 by Damage A Initiation in red and Damage B Initiation in purple.

The Figure 2 presents also the progress of the damage at a macroscopic scale. The strain fields $\varepsilon_{y y}$ and $\varepsilon_{x x}$, obtained in the top ply for a crosshead displacement of $12 \mathrm{~mm}$, have a rhombus shape (Point A) which is typical of a carbon woven $\pm 45^{\circ}$ subject to a tensile load. Then, for a crosshead displacement of $17.5 \mathrm{~mm}$ (Point B), two bands of cracking, following the edges of the rhombus area, emerge in the laminate. But, the laminate does

not break directly. A rotation and a distortion of the bundles is noticeable (Point C) until a crosshead displacement of $21.1 \mathrm{~mm}$ for which breaks of fibers finally propagate along one of the two cracked bands (Point D). 
Pseudo-plastic behaviour in plane shear.

The emergence of irreversible strains in the carbon woven is taken into account in the model through the introduction of a pseudo-plasticity criterion on the in-plane shear stress based on an isotropic hardening using a classic elastic prediction and a plastic correction. An elastic field is defined by :

$$
f=\left|\tau_{12}\right|-K_{\text {plas }} p^{\beta}-\tau_{0}
$$

where $\tau_{12}$ is the in-plane shear stress, $\tau_{0}$ is the plastic strength, $\left(K_{\text {plas }}, \beta\right)$ are parameters of the plastic hardening law and $p$ the cumulative plastic strain. Thus, if $f>0$, the plastic correction is performed throught the update of the plastic variables $\gamma_{12}^{p}$ and $p$, based on a Newton-Raphson iterative scheme, with $\gamma_{12}^{p}$ the plastic shear strain defined by :

$$
\gamma_{12}=\gamma_{12}^{e}+\gamma_{12}^{p}
$$

where $\gamma_{12}$ is the total shear strain and $\gamma_{12}^{e}$ is the elastic shear strain.

\section{Shear damaging.}

In order to modelize the two types of damage mentioned above, two shear damage variables are added in the modelling and came degrade the shear modulus :

$$
G_{12}=\left(1-d_{12}^{a}-d_{12}^{b}\right) G_{12}^{0}
$$

They depend on thermodynamical function, as it is typically used [32, 33] :

$$
\left\{\begin{array}{l}
d_{12}^{a}=d_{12}^{a^{\max }} \times\left(1-\exp \left(-\frac{\left\langle\sqrt{Y_{12}}-\sqrt{Y_{0}}\right\rangle_{\geq 0}}{\sqrt{Y_{c}}}\right)\right) \\
d_{12}^{b}=\max \left(\exp \left(\frac{\left\langle\sqrt{Y_{12}}-\sqrt{Y_{0 b i s}}\right\rangle_{\geq 0}}{\sqrt{Y_{c b i s}}}\right), 1\right)
\end{array}\right.
$$

where $Y_{0}$ (respectively $Y_{0 b i s}$ ) and $Y_{c}$ (respectively $Y_{c b i s}$ ) are parameters of damage threshold and damage speed of $d_{12_{a}}$ (respectively $d_{12_{b}}$ ). $d_{12_{a}}^{\max }$ is the maximal limit of $d_{12_{a}}$. This limit has been introduced for the damage $\mathrm{A}$ because it is not responsible for the final break of the laminate.

Here, the shear strain energy is only due to shear stress and the coupling with the stresses in the other directions is neglected. Thus, the thermodynamical function $Y_{12}$ is defined by: 


$$
Y_{12}=\frac{\partial W_{12}}{\partial d_{12}}
$$

where $d_{12}=d_{12}^{a}+d_{12}^{b}$ and $W_{12}$ is the shear strain energy defined by :

$$
W_{12}=\frac{\tau_{12}^{2}}{2 G_{12}^{0}\left(1-d_{12}\right)}
$$

Hence :

$$
Y_{12}=\frac{1}{2} G_{12}^{0} \gamma_{12}^{e 2}
$$

Furthermmore, during a tensile test on a $\pm 45^{\circ}$ woven carbon laminate, when the resin is totally damaged, that amounts to saying that $G_{12}=0$. However, in the model, there already are two damage variables $d_{1}$ and $d_{2}$ in order to modelize the resin damaging in the warp and weft directions and which come to degrade stifnesses $E_{11}$ and $E_{22}$ by $E_{11}=\left(1-d_{1}\right) E_{11}^{0}$ and $E_{22}=\left(1-d_{2}\right) E_{22}^{0}$. Even if $G_{12}=0$, the load is going to be recovered because $E_{11}$ and $E_{22}$ are not equal to zero. So, the two shear damage variables are also used to degrade $E_{11}$ and $E_{22}$, and the shell and the bending matrix are expressed by :

$$
\left[\begin{array}{ccc}
\frac{\left(1-d_{1}\right)\left(1-d_{12}^{a}-d_{12}^{b}\right) E_{1}}{1-\left(1-d_{1}\right)\left(1-d_{2}\right)\left(1-d_{12}^{a}-d_{12}^{b}\right) \nu_{12} \nu_{21}} & \frac{\left(1-d_{1}\right)\left(1-d_{2}\right)\left(1-d_{12}^{a}-d_{12}^{b}\right) \nu_{21} E_{1}}{1-\left(1-d_{1}\right)\left(1-d_{2}\right)\left(1-d_{12}^{a}-d_{12}^{b}\right) \nu_{12} \nu_{21}} & 0 \\
\frac{\left(1-d_{1}\right)\left(1-d_{2}\right)\left(1-d_{12}^{a}-d_{12}^{b}\right) \nu_{12} E_{2}}{1-\left(1-d_{1}\right)\left(1-d_{2}\right)\left(1-d_{12}^{a}-d_{12}^{b}\right) \nu_{12} \nu_{21}} & \frac{\left(1-d_{2}\right)\left(1-d_{12}^{a}-d_{12}^{b}\right) E_{2}}{1-\left(1-d_{1}\right)\left(1-d_{2}\right)\left(1-d_{12}^{a}-d_{12}^{b}\right) \nu_{12} \nu_{21}} & 0 \\
0 & 0 & \left(1-d_{12}^{a}-d_{12}^{b}\right) G_{12}^{0}
\end{array}\right]
$$

Angle criterion.

Experimentally, rotation and distorsion of the bundles appear once the resin is totally cracked and meta-delamination emerges between warp and weft [31]. However, in the modelling, this meta-delamination is taken into account by a damage variable which degrades the stiffnesses of the shell element. When the resin is totally cracked, that is to say that the shell element is broken, the finite element is suddenly distorted (Figure 3). But, a link between the rod elements of the warp and weft still remains. Moreover, the rod elements don't recover a lot of load, thus they can't elongate and the break criterion on tensile strain can't be reached for these rods. So, a criterion on the minimum or maximum angle between the rods has been added in order 
to represent this distortion : if $\phi_{i} \leq 90^{\circ}-\phi_{\max }$ or $\phi_{i} \geq 90^{\circ}+\phi_{\max }$ then break of the bar elements constituting the angle.

\section{Identification and validation.}

Before realizing simulations on the impacted laminates experimentally tested in the Part I, the damaging pseudo-plastic law has to be validated trought the identification of the several parameters presented in the Table 3.

For this purpose, a simulation of tensile test on two plies of woven carbon oriented at $\pm 45^{\circ}$ is made. The sizes of numerical sample are the same as the experimental sample $(100 \mathrm{~mm} \times 200 \mathrm{~mm})$ and numerical tabs $(100 \mathrm{~mm} \times 20 \mathrm{~mm})$ are added in order to avoid edge effects throughout the tensile simulation. They are modelized by an elastic Johnson-Cook law with an infinite break limit and a Young's modulus corresponding to the lamination plus six plies of glass woven at $\pm 45^{\circ}$. In the strategy of the semi-continuous model, the mesh size respects the woven fabric pattern. So, the mesh size of the modelling is $1.4 \mathrm{~mm} \times 1.4 \mathrm{~mm} \times 0.36 \mathrm{~mm}$. The computation is performed with the explicit finit element code RADIOSS on 60 cores from HPC resources.

The Figure 4 shows a good correspondance between the numerical and experimental curves, with a good stiffness of the laminate and a good progress of the load, for a cycled and a non-cycled quasi-static tensile tests on two plies of carbon woven at $\pm 45^{\circ}$, but also a numerical fracture surface close to those obtained experimentally.

The Figure 5 shows the damage development during the simulation. As for the experimental testing, cracking bands appear first in the laminate (Point A), which results in deletions of the shell elements in the model. Then, the resin being totally cracked, these elements endure a distorsion (Point B-B') until the criterion on the angle between the rod elements is reached (Point B"). From this time, the rod elements are deleted and the finite element is totally removed. Finally, fibres breakings propagate along the cracked bands, what leads to the final break of the laminate (Point $\mathrm{C}$ ). 


\section{Post-impact quasi-static tensile simulations}

\subsection{Model}

Each configuration experimentally tested in the Part 1 (Tables 1-2) is now modelized. The numerical sample is the same as the simulations carried out for the validation of the damaging pseudo-plastic law. Each ply of the sample are modelized separately with a difference on the mesh size between carbon and glass woven, the measured woven fabric pattern being differend according to the material. So, the mesh size of the modelling is $1.4 \mathrm{~mm} \times 1.4 \mathrm{~mm} \times 0.36 \mathrm{~mm}$ for the carbon woven and $0.5 \mathrm{~mm} \times 0.5 \mathrm{~mm} \times 0.31 \mathrm{~mm}$ for the glass woven. Thus, the highest required number of developed finite elements among all the tested configurations is 160 000. Finally, between two plies of different nature and/or orientation (with different meshings), a kinematic condition is added in order to connect the nodes of these two plies.

The conditions of the impact simulation are the same as the ones used for the experimental test presented in Part I. The impactor is modelized by a halph-sphere with an elastic law (with the steel characteristics : $\rho_{\text {steel }}=7900$ $\mathrm{kg} / \mathrm{m}^{3}, E_{\text {steel }}=210 \mathrm{GPa}$ and $\left.\nu_{\text {steel }}=0.3\right)$, a contact condition is used between the sample and the impactor and the double frame is modelized by two rigid wall in contact with the bottom and the top of the sample. The different energies of impact tested are gathered in the Table 4.

For the tensile test, on side of the tabs is embedded and the other is subject to an imposed velocity.

The computations are performed with the explicit finit element code RADIOSS on 180 cores from HPC resources.

The method to simulate the post-impact quasi-static tensile simulation is first to realize the impact simulation on the sample and then to initiate the tensile simulation with the damaged state obtained at the end of the impact simulation. A Python script has been developped for purposes of doing that.

\subsection{Single-material laminates}

Before testing the semi-continuous modelling on the hybrid laminates, a validation is first realized on the monomaterial laminates C0C0, C45C45, 
C45C0 and V0V0 for one energy of impact. The propagation of the postimpact damage and the load - crosshead displacement curves numerically obtained are compared to the experimental one for each configuration.

\subsubsection{Drop weight impact simulations}

In a first time, impact simulations are made for each monomaterial laminates. The Figure 6 shows a comparaison between experimental and numerical fracture shapes after impact. On the numerical results, the red represents the fibres breaks and the rest matrix cracks which occurs around these breaks. The model is able to represent the good shape of damage after impact : the fibres breaks are well oriented and follow the direction of the plies. The damages sizes are correct with maximal relative error lower than $20 \%$. In this case, the initial damage states used for the next tensile simulations are similar to the experimental ones what confirms that the two adds-on implemented in the semi-continuous model don't modify the modelling of impact behaviour.

\subsubsection{Post-impact quasi-static tensile simulations}

The fracture surfaces (identical for the upper and lower plies) and the corresponding load - crosshead displacement curves obtained for the postimpact tensile simulations on the single-material laminates are presented in Figure 7. For the configuration $\mathrm{C} 0 \mathrm{C} 0, \mathrm{C} 45 \mathrm{C} 45$ and V0V0, the propagation of the post-impact damage is tranversal and for the configuration $\mathrm{C} 45 \mathrm{C} 0$, the direction of the propagation is mainly transversal and slightly guided by the carbon ply at $\pm 45^{\circ}$. Furthermore, for $\mathrm{C} 45 \mathrm{C} 0$, the model manages to represent the emergence of little vertical break of fibres thanks to the introduction of the compressive criterion on the rod elements. In any case, the final break of the laminate is due to fibres breaks propagation. 
Concerning the numerical load - crosshead displacement curves, they are identical to the experimental ones for all the single-material laminates. The stiffness of the damaged sample is correct and the final break occurs for the good load and crosshead displacement (the relative error on the displacement is only $8 \%$ for $\mathrm{C} 0 \mathrm{C} 0,10 \%$ for $\mathrm{C} 45 \mathrm{C} 45,5 \%$ for $\mathrm{C} 45 \mathrm{C} 0$ and $3 \%$ for G0G0). Thus, the pseudo-plastic damage law, developed and presented previously, provide thus the good damage propagation in the impacted samples C45C45 and $\mathrm{C} 45 \mathrm{C} 0$.

So, the semi-continuous modelling is validated for the monomaterial laminates and can be now tested for the hybrid laminates.

\subsection{Hybrid laminates}

In this section, the semi-continuous modelling is first validated on the hybrid laminates for one energy of impact. As for the monomaterial laminates, the post-impact damage propagation and the corresponding load - crosshead displacement curves are compared to the experimental ones. Then, the simulations are used to explain the particular behaviour of the configuration G0C45C45 and the differences observed for the configuration G0C45C0 depending on the energy of impact.

\subsubsection{Drop weight impact simulations}

As for the single-material laminates, the Figure 8 shows a comparaison between experimental and numerical fracture shapes after impact for the hybrid laminates. The fibres breaks in the lower ply follow the direction of this ply and the cracked area in the upper ply has the same shape than those experimentally obtained, with a maximal relative error on the damages sizes lower than 15\%. Moreover, the numerical and experimental load displacement curves are identical, what indicate that the damaging scenario during the drop weight impact is correctly taken into account with the model.

\subsubsection{Post-impact quasi-static tensile simulations}

The fracture surfaces (identical for the upper and lower plies) and the corresponding curves obtained for hybrid laminates are presented on the Figure 9. As for the monomaterial laminates, the fracture surfaces numerically obtained for the hybrid laminates are identical to the experimental ones. The propagation of the post-impact damage for $\mathrm{G} 0 \mathrm{C} 45 \mathrm{C} 45$ is at $\pm 45^{\circ}$ 
while for $\mathrm{G} 0 \mathrm{C} 45 \mathrm{C} 0$, it starts at $\pm 45^{\circ}$ and finishes horizontally. Moreover, the curves show that the stiffness of the damaged sample is correct. The influence of the pseudo-plastic behaviour of the carbon ply $\pm 45^{\circ}$ is noticeable for the laminate G0C45C45 with a non-linear curve althought for the laminate G0G45C0, the influence is not visible, the curve being linear.

The strain fields numerically observed in each ply of the configuration G0C45C45 give the damage propagation scenario during the tensile simulation (Figure 10). First, the strain field $\varepsilon_{y y}$ in the upper glass ply is very similar to those observed in the upper ply of the configuration $\mathrm{C} 45 \mathrm{C} 45$ and very different to those observed in the upper ply of the configuration V0V0 at the same crosshead displacement (Point A). It indicates that the elongation of the glass ply is piloted by the elongation of the carbon plies. Then, just before the first fall of load (Point B), areas of compressive strains are visible around the damaged zone in the glass ply. The new criterion on compressive strain of rods is reached here by some elements what initiate the propagation in this ply by compressive fibres breaks at $\pm 45^{\circ}$. After that, compressive and tensile fibres breaks propagate what leads to the breaks at $\pm 45^{\circ}$ of the glass ply and the cracking at $\pm 45^{\circ}$ of the carbon plies on the corresponding band and corresponds to the first fall of load on the curve (Point C). However, the carbon plies don't break what localize the strains on the cracked band. They are able to recover the load what it is visible on the curve by a plateau betwenn the Points C and D. Finally, the two carbon plis break at $\pm 45^{\circ}$ along the cracked band what coincide which the final fall of the load on the curve (Point E).

In summary, the break of the impacted laminate $\mathrm{G} 0 \mathrm{C} 45 \mathrm{C} 45$ is in three steps (first the glass ply breaks at $\pm 45^{\circ}$, then the two carbon plies recover the load and finally these carbon plies break at $\pm 45^{\circ}$ ) and this scenario is connected to the curve evolution. Well, the numerical curve evolution is close to the experimental one (Figure 9) : the relative error on the displacement is $8 \%$ for the first fall of load, $3 \%$ for the final fall of load and the relative error on the load is $13 \%$ for the plateau. So, it indicates that, during the simulation, each break occurs at the same time as for the experimental test.

The results of the numerical simulations are also used to explain the propagation of the post-impact damage in the laminate G0C45C0. The Figure 11 presents the evolution of the damage in each ply of a $4 \mathrm{~J}$ impacted laminate 
during the tensile simulation. The damage starts to propagate in the glass ply from the fibres breaks generated by the impact. After that, fibres breaks initiate in the lower carbon ply but not in the middle ply. Then, propagation of compressive fibres breaks at $\pm 45^{\circ}$ is noticeable in the glass ply. Thus, the beginning of the damage in the glass ply is similar to the the propagation in the laminate G0C45C45. Finally, fibres breaks appear in the middle carbon ply, what causes the final horizontal and simultaneous propagation in the three plies. The middle carbon ply is thus the critical ply of the laminate.

The final break of the laminate corresponds to the unique fall of load on the load - crosshead displacement curve (Figure 9). The numerical and experimental curves being identical (the relative error on the break displacement is only $5 \%$ ), it means that the break of the numerical sample occurs at the same time in comparison to the experimental one.

The modelling is also used to explain the difference of fractured surfaces observed in the Part I for the laminate G0C45C0 depending on the energy of impact. In fact, for $1 \mathrm{~J}$ and $2.25 \mathrm{~J}$ impacted samples, the propagation of the damage during the tensile test is horizontal althought, from $4 \mathrm{~J}$, the damage starts to propagate at $\pm 45^{\circ}$ and finishes horizontally. For an energy of $1 \mathrm{~J}$ (Figure 12), the initial damage is almost absent in the upper glass ply and the fibres breaks start to propagate in the lower carbon ply. And after that, they start to propagate quasi-simultaneously in the glass ply and the middle carbon plies. The compressive fibres breaks do not have the time to appear in the glass ply and the three plies break horizontally and simultaneously.

For an energy of $2.25 \mathrm{~J}$ (Figure 13), even if there is no fibres breaks in the glass ply after the impact, the resin damaging is quite extanded, what initiates the propagation of fibres breaks in this ply during the tensile simulation. But, quasi-simultaneously, the propagation of fibres breaks is also initiated in the lower and middle carbon plies. So, the final break of the three plies is, in this case too, horizontal and simultaneous.

Finally, the Figure 14 links the fracture surface obtained after the tensile simulation with the post-impact damage and the ply in which the damage initiates :

- When there is no fibre break and almost no resin damaging in the glass 
ply, the damage propagation initiates in the lower carbon ply. Then, fibres breaks initiate simultaneously in the glass ply and in the middle carbon ply what lead to a transversal fracture surface of the laminate, the middle carbon ply being the critical ply of the laminate.

- When there is no fibres breaks and resin damaging quite developed in the glass ply, the damage propagation initiates quasi-simultaneously in the glass ply and the middle and lower carbon plies, what leads also to a transversal fracture surface.

- When there are fibres breaks in the glass ply, the damage propagation initiates in this ply and then in the lower carbon ply. Fibres breaks starts to propagate at $\pm 45^{\circ}$ as long as fibres breaks propagation are not initiated in the middle carbon ply. Once they are initiated, the propagation finishes horizontally in the three plies.

\section{Conclusion}

In this article, post-impact quasi-static tensile tests have been modeled with the semi-continuous strategy. The modelling manages to represent on the one hand the propagation of resin crackings and on the other hand the propagation of bundles breakages during the tensile simulation while taking into account the laminate hybridization, especially through the implementation of a compressive strain criterion for the bundle breakage and of an original damaging pseudo-plastic law in plane-shear able to represent different types of shear damage visible experimentally.

The damaging pseudo-plastic law has been identified and validated with cycled and non-cycled quasi-static tensile tests on two undamaged carbon plies $\pm 45^{\circ}$. Then, the model has been validated through post-impact quasistatic tensile simulations on all the configurations experimentally tested in Part 1 (monomaterial and hybrid laminates). The model well represents the propagation of the post-impact damage. The fracture surfaces and the load - crosshead displacement curves well correlate the experimental results.

The first major contribution of this study is to provide a modelling that simulates as well impact as post-impact tensile tests. The initial damage state of the tensile simulation is the damage state obtained after the impact simulation and is not introduced through experimental observations. 
The second major contribution of this article is to provide a more accurate analysis of the post-impact damage scenario based on the analysis of numerical results. For instance, concerning the hybrid laminate G0C45C0, the analyzis of the results provided by the modelling helps us to understand that the two post-impact damage propagations observed for low and higher impact energies are directly related to the fibre breakage in the glass ply. Moreover, in any case, it can be observed from the result that the middle carbon ply is the critical ply of the laminate. 


\section{References}

[1] G. Husman, J. Whitney, J. Halpin, Residual strength characterization of laminated composites subjected to impact loading, Tech. rep., Air Force Materials Laboratory (1975).

[2] Y. Xiong, C. Poon, P. Straznicky, H. Vietinghoff, A prediction method for the compressive strength of impact damaged composite laminates, Composite Structures 30 (4) (1995) 357 - 367.

[3] N. Naik, R. Ramasimha, Estimation of compressive strength of delaminated composites, Composite Structures 52 (2001) 199-204.

[4] B. Ostré, C. Bouvet, C. Minot, J. Aboissière, Experimental analysis of cfrp laminates subjected to compression after edge impact, Composite Structures 152 (2018) $767-778$.

[5] B. Qi, I. Herszberg, An engineering approach for predicting residual strength of carbon/epoxy laminates after impact and hygrothermal cycling, Composite Structures 47 (1) (1999) 483 - 490.

[6] G. Caprino, V. Lopresto, The significance of indentation in the inspection of carbon fibre-reinforced plastic panels damaged by low-velocity impact, Composites Science and Technology 60 (7) (2000) 1003 - 1012.

[7] C. Soutis, P. Curtis, Prediction of the post-impact compressive strength of cfrp laminated composites, Composites Science and Technology 56 (6) (1996) $677-684$.

[8] M. De Moura, J. Gon,alves, A. António, Modeling compression failure after low velocity impact on laminated composites using interface elements, Journal of Composite Materials 31 (1997) 1462-1479.

[9] F. Habib, A new method for evaluating the residual compression strength of composites after impact, Composite Structures 53 (2001) 309-316.

[10] V. Hawyes, P. Curtis, C. Soutis, Effect of impact damage on the compressive response of composite laminates, Composites Part A: Applied Science and Manufacturing 32 (2001) 1263-1270. 
[11] H. Suemasu, W. Sasaki, T. Ishikawa, Y. Aoki, A numerical study on compressive behavior of composite plates with multiple circular delaminations considering delamination propagation, Composites Science and Technology 68 (12) (2008) 2562 - 2567.

[12] G. Davies, D. Hitchings, T. Besant, A. Clarke, C. Morgan, Compression after impact strength of composite sandwich panels, Composite Structures 63 (1) (2004) $1-9$.

[13] S.-X. Wang, L.-Z. Wu, L. Ma, Low-velocity impact and residual tensile strength analysis to carbon fiber composite laminates, Materials \& Design 31 (1) (2010) 118 - 125.

[14] E. Gonzàlez, P. Maimí, P. Camanho, A. Turon, J. Mayugo, Simulation of drop-weight impact and compression after impact tests on composite laminates, Composite Structures 94 (11) (2012) 3364 - 3378.

[15] T. D. Dang, S. R. Hallett, A numerical study on impact and compression after impact behaviour of variable angle tow laminates, Composite Structures 96 (2013) $194-206$.

[16] S. Rivallant, C. Bouvet, N. Hongkarnjanakul, Failure analysis of cfrp laminates subjected to compression after impact: Fe simulation using discrete interface elements, Composites Part A: Applied Science and Manufacturing 55 (2013) 83 - 93 .

[17] W. Tan, B. G. Falzon, L. Chiu, M. Price, Predicting low velocity impact damage and compression-after-impact (cai) behaviour of composite laminates, Composites Part A: Applied Science and Manufacturing 71 (2015) $212-226$.

[18] E. Panettieri, D. Fanteria, F. Danzi, Delaminations growth in compression after impact test simulations: Influence of cohesive elements parameters on numerical results, Composite Structures 137 (2016) 140 147.

[19] M. Montero, E. Barjasteh, H. Baid, C. Godines, F. Abdi, K. Nikbin, Multi-scale impact and compression-after-impact modeling of reinforced benzoxazine/epoxy composites using micromechanics approach, Journal of Multiscale Modelling 8 (1) (2017) 1-26. 
[20] N. Dubary, C. Bouvet, S. Rivallant, L. Ratsifandrihana, Damage tolerance of an impacted composite laminate, Composite Structures 206 (2018) $261-271$.

[21] H. Yan, C. Oskay, A. Krishnan, L. R. Xu, Compression-after-impact response of woven fiber-reinforced composites, Composites Science and Technology 70 (14) (2010) 2128 - 2136.

[22] P. Mendes, M. Donadon, Numerical prediction of compression after impact behavior of woven composite laminates, Composite Structures 113 (2014) $476-491$.

[23] G. Papanicolaou, D. Chalkias, A. Koutsomitopoulou, Low energy impact and post impact behavior of epoxy matrix-woven flax fabric composites, U.P.B Sci. Bull., Series D 78 (1) (2016) 25-36.

[24] C. Colombo, L. Vergani, A micromechanical approach to evaluate the post-impact residual stiffness of woven composites, Journal of Composite Materials 50 (7) (2016) 971-984. arXiv:https://doi.org/10.1177/0021998315585587.

[25] P. Navarro, F. Pascal, J. Aubry, S. Marguet, J.-F. Ferrero, S. Lemaire, P. Rauch, Semi-continuous approach for the study of impacts on woven composite laminates: Modeling interlaminar behavior with a specific interface element, International Journal of Impact Engineering 75 (2015) $184-193$.

[26] F. Pascal, P. Navarro, S. Marguet, J.-F. Ferrero, On the modelling of low to medium velocity impact onto woven composite materials with a 2d semi-continuous approach, Composite Structures 134 (2015) 302 310 .

[27] F. Pascal, O. Dorival, P. Navarro, S. Marguet, J.-F. Ferrero, Impact damage prediction in thin woven composite laminates - part i: Modeling strategy and validation, Composite Structures 190 (2018) $32-42$.

[28] F. Pascal, A. Rogani, B. Mahmoud, P. Navarro, S. Marguet, J.-F. Ferrero, Impact damage prediction in thin woven composite laminates - part ii: Application to normal and oblique impacts on sandwich structure, Composite Structures 190 (2018) 43 - 51. 
[29] S. Ek,si, K. Genel, Comparison of mechanical properties of unidirectional and woven carbon, glass and aramid fiber reinforced epoxy composites, Acta Physica Polonica A 132 (2017) 879-882.

[30] M. Karahan, Investigation of damage initiation and propagation in $2 \times 2$ twill woven carbon/epoxy multi-layer composites, Textile Research Journal 81 (4) (2011) 412-428.

[31] A. Bogdanovich, M. Karahan, S. V. Lomov, I. Verpoest, Quasi-static tensile behavior and damage of carbon/epoxy composite reinforced with 3d non-crimp orthogonal woven fabric, Mechanics of Materials 62 (2013) $14-31$.

[32] C. Hochard, J. Payan, C. Bordreuil, A progressive first ply failure model for woven ply cfrp laminates under static and fatigue loads, International Journal of Fatigue 28 (10) (2006) 1270 - 1276.

[33] C. Hochard, Y. Thollon, A generalized damage model for woven ply laminates under static and fatigue loading conditions, International Journal of Fatigue 32 (1) (2010) 158 - 165. 


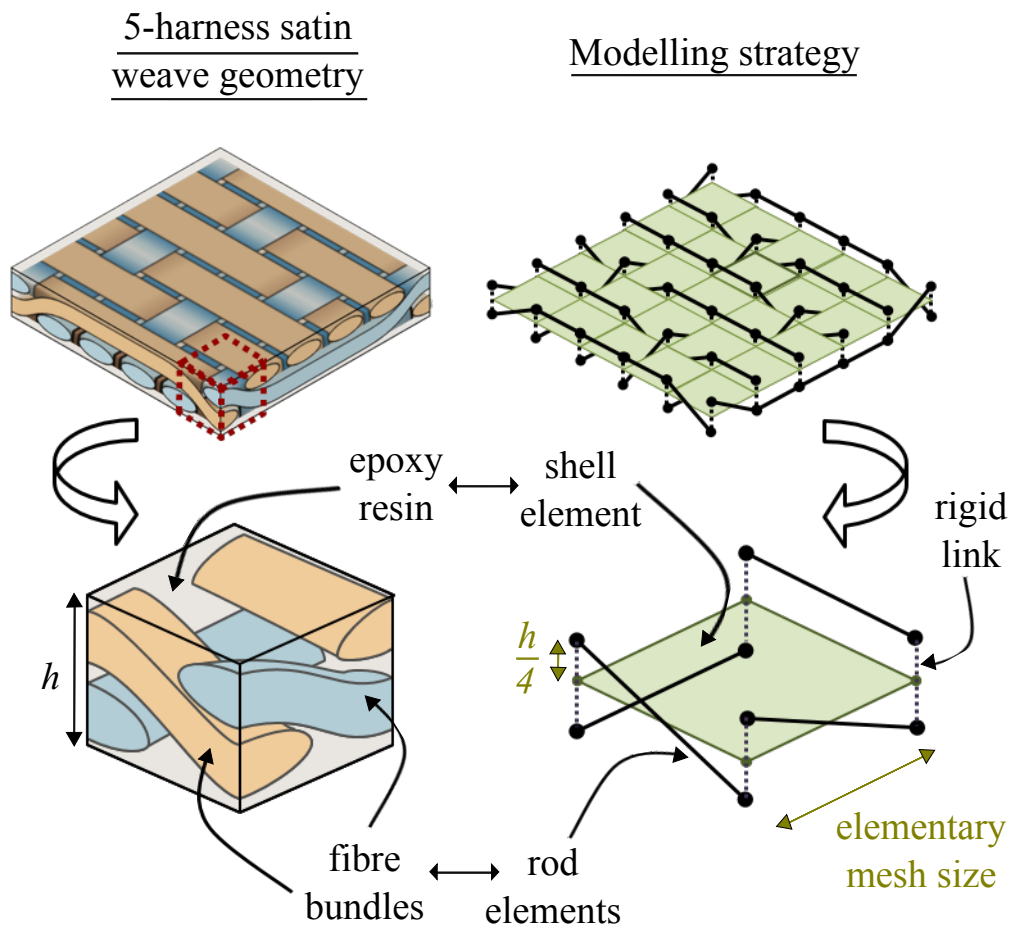

Figure 1: Modelling strategy of the woven ply 

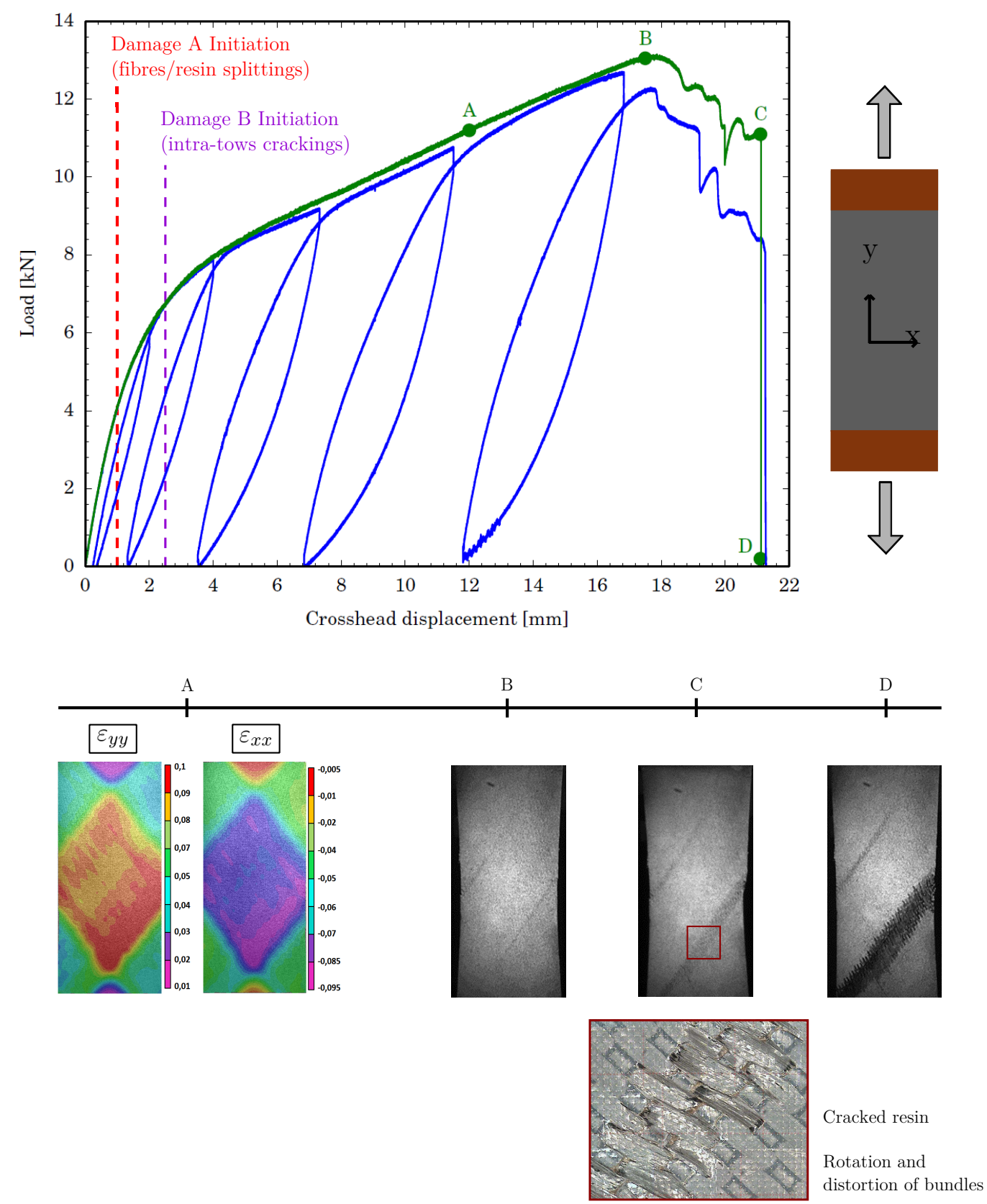

Figure 2: Emergence and progress of shear damage during a quasi-static tensile test on two plies of carbon/epoxy woven $\pm 45^{\circ}$ 


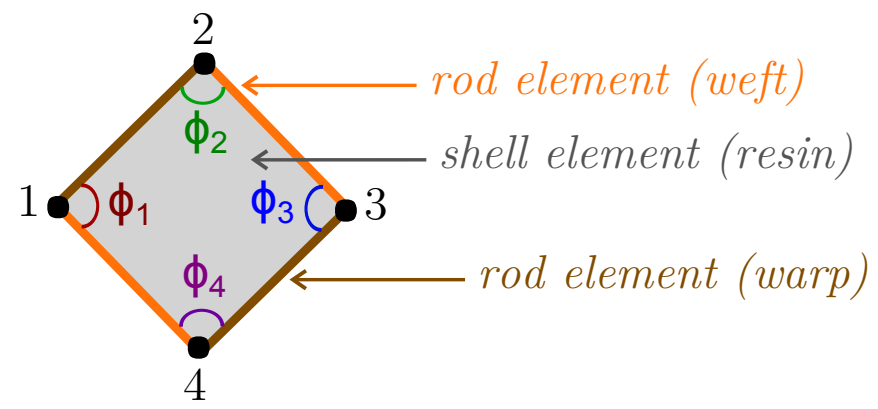

undistorted element

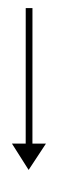

shell element deletion (resin breakage)

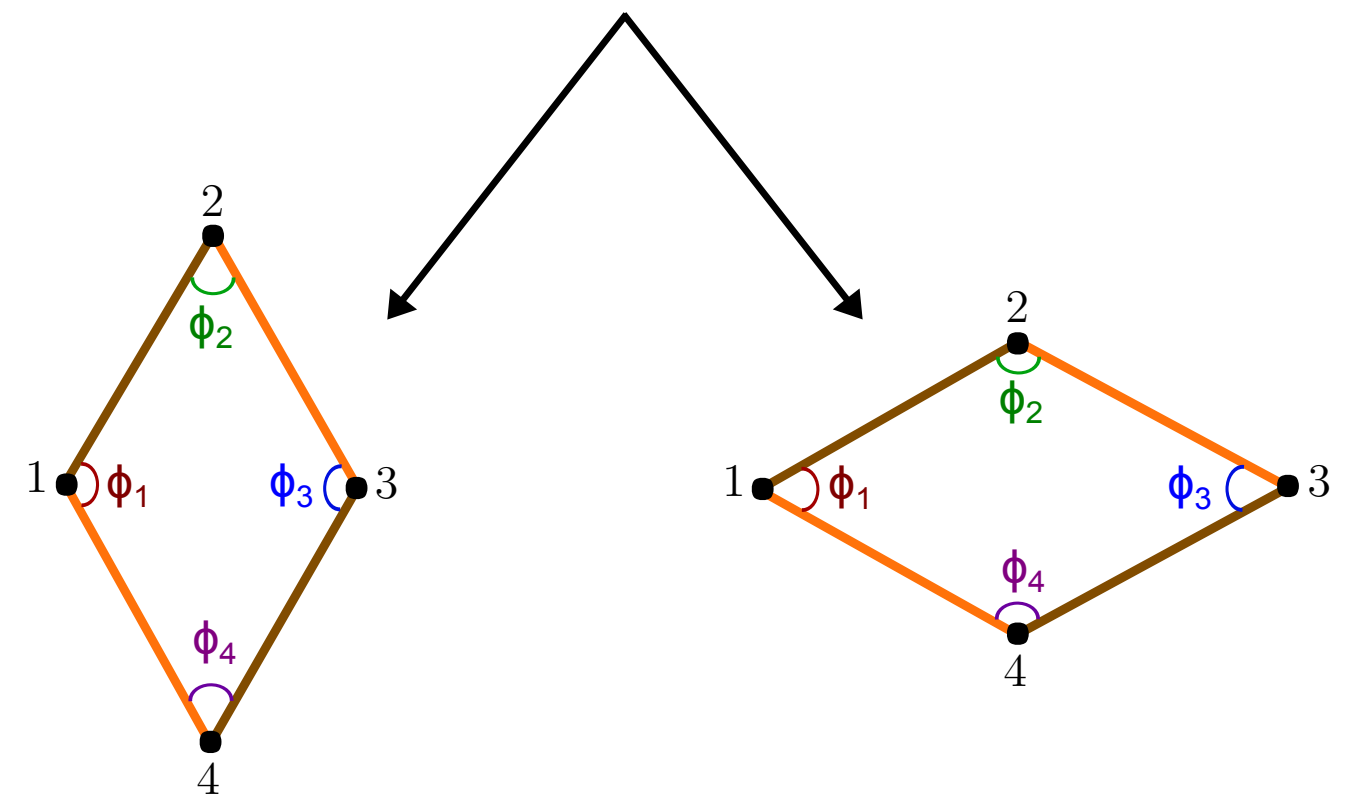

distorted element

distorted element

$\downarrow \phi_{2} \phi_{4}$ and $\nearrow \phi_{1} \phi_{3}$

$\nearrow \phi_{2} \phi_{4}$ and $\downarrow \phi_{1} \phi_{3}$

Figure 3: Distorsion of an element at the break of the resin 


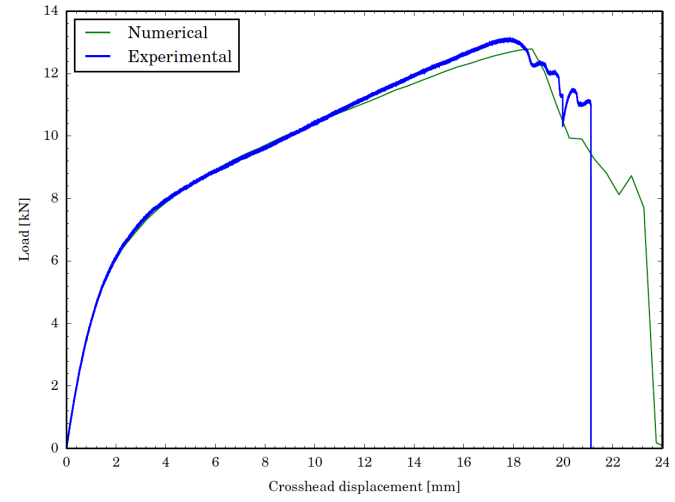

(a)

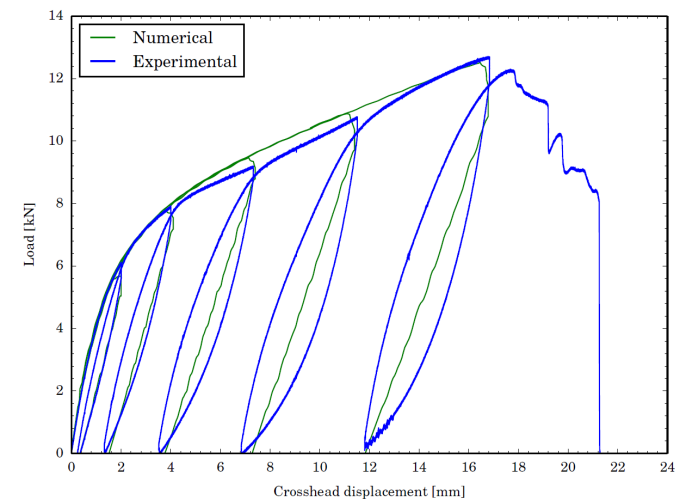

(b)

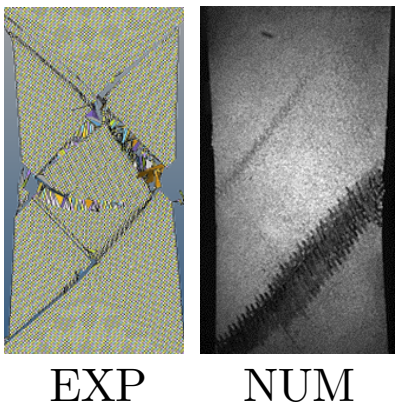

(c)

Figure 4: Comparison of numerical and experimental results after (a) normal (b) cycled quasi-static tensile tests on two plies of carbon woven at $\pm 45^{\circ}$ 


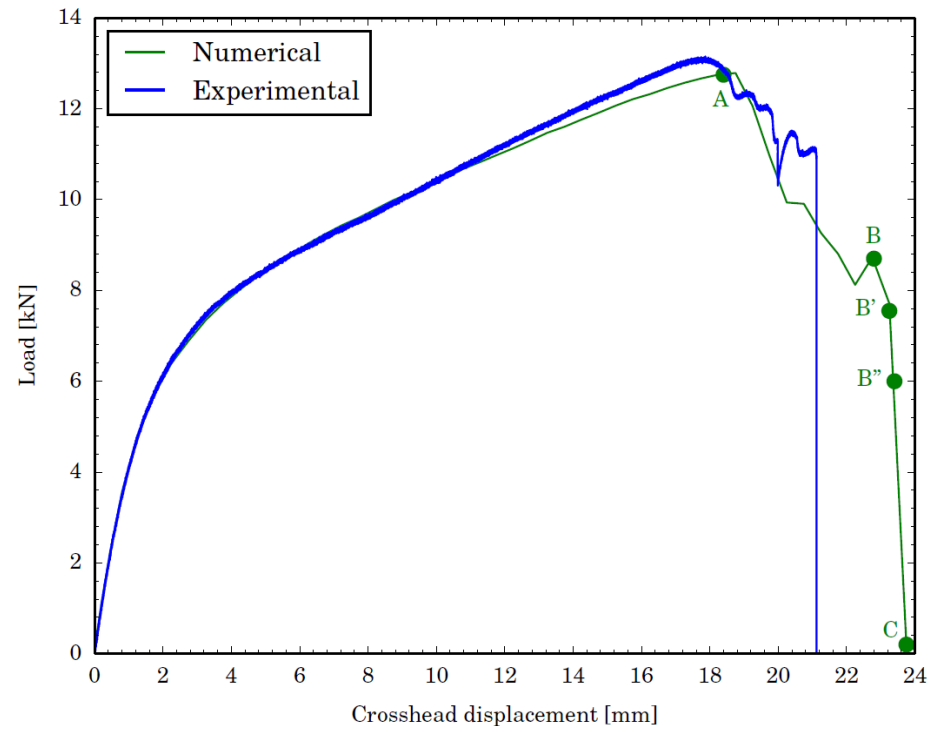

A

Emergence of the first cracking bands at $45^{\circ}$

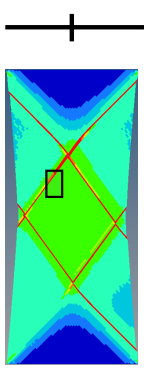

Damage propagation Final break
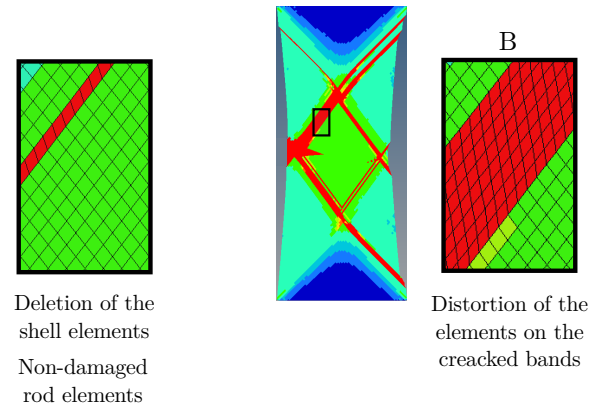

Distortion of the Increase of the elements on the distortion of creacked bands some elements
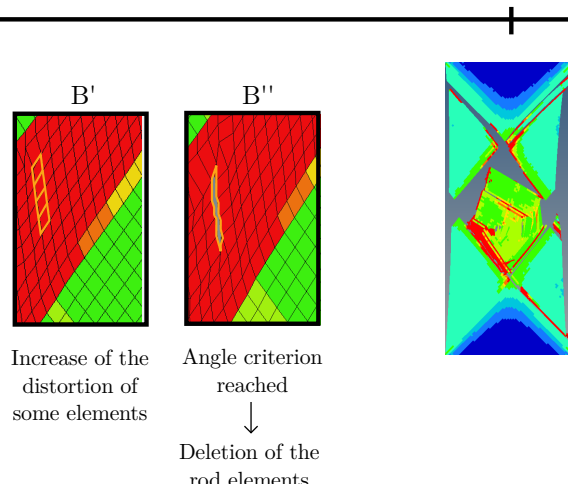

Figure 5: Damage evolution during the quasi-static tensile simulation on two plies carbon/epoxy $\pm 45^{\circ}$ 


\begin{tabular}{|c|c|c|c|c|}
\hline \multirow[b]{2}{*}{ configuration } & \multicolumn{2}{|c|}{ EXPERIMENTAL } & \multicolumn{2}{|c|}{ NUMERICAL } \\
\hline & upper ply & lower ply & upper ply & lower ply \\
\hline C0C0 (4J) & $\begin{array}{c}\underset{15,6 \mathrm{~mm}}{\mathrm{~m}} \\
14,1 \mathrm{~mm}\end{array}$ & 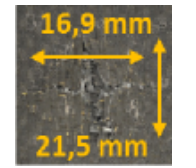 & $\begin{array}{l}4 \\
18,2 \mathrm{~mm}\end{array}$ & $\begin{array}{c}17 \mathrm{~mm} \\
16,8 \mathrm{~mm} \\
15\end{array}$ \\
\hline C45C45 (4J) & & & & \\
\hline $\mathrm{C} 45 \mathrm{C} 0(4 \mathrm{~J})$ & $\begin{array}{r}6,4 \mathrm{~mm} \\
6 \\
5,5 \mathrm{~mm}\end{array}$ & $\begin{array}{c}16,3 \mathrm{~mm} \\
18,8 \mathrm{~mm} \\
1\end{array}$ & $9,8 \mathrm{~mm}$ & $\underset{18,4 \mathrm{~mm}}{\stackrel{17 \mathrm{~mm}}{\longrightarrow}}$ \\
\hline G0G0 (4J) & 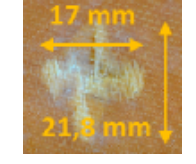 & $\begin{array}{l}\frac{16,2,2 \mathrm{~mm}}{24,3 \mathrm{~mm}} \\
2\end{array}$ & 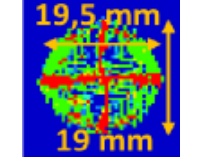 & 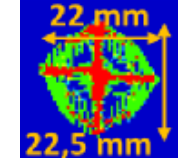 \\
\hline
\end{tabular}

Figure 6: Drop weight impact results on single-material laminates - Experimental and numerical comparaison 


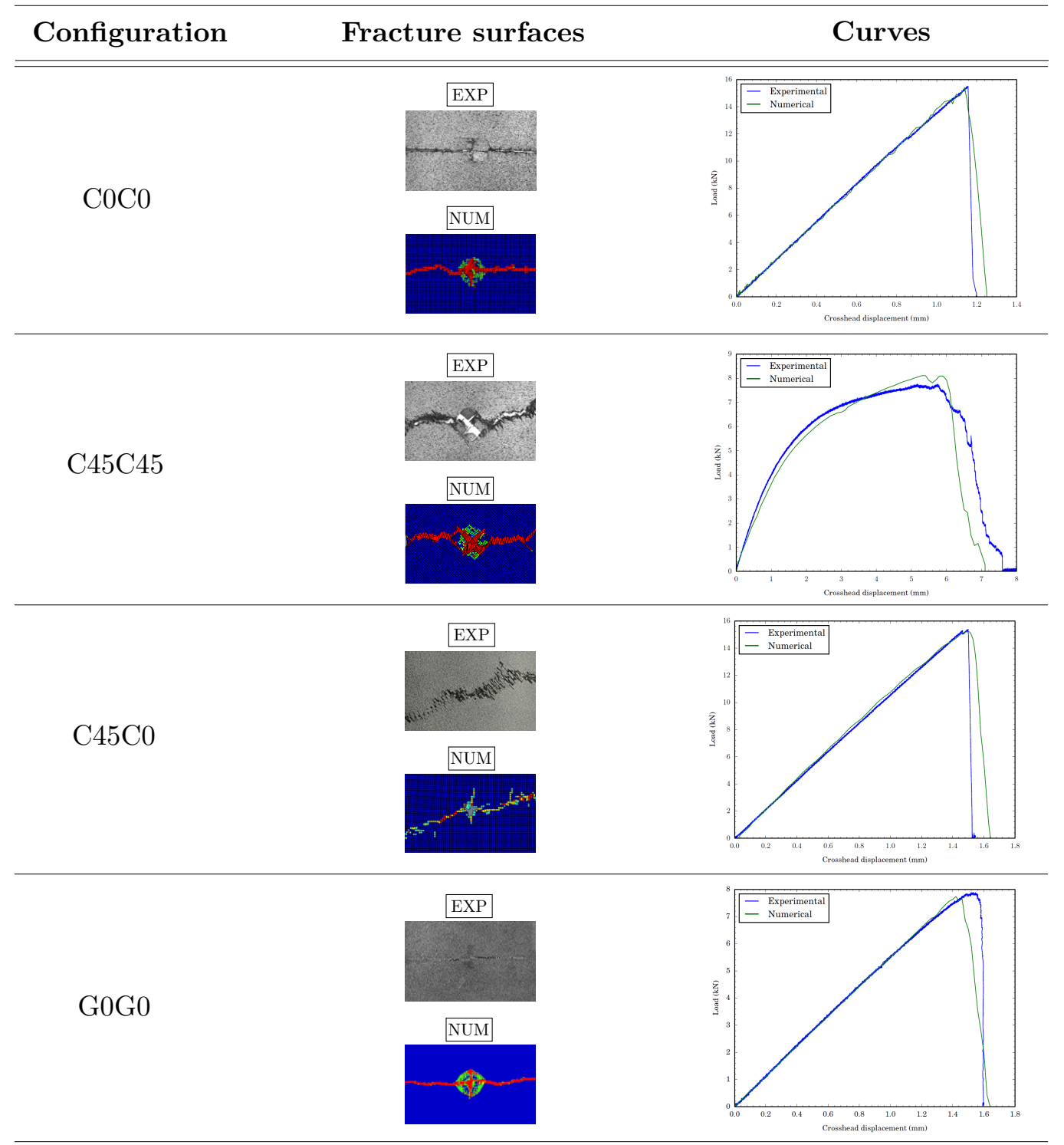

Figure 7: Fracture surfaces (identical for the upper and lower plies) and curves obtained after tensile tests on impacted single-material laminates - Comparison between the experimental results 


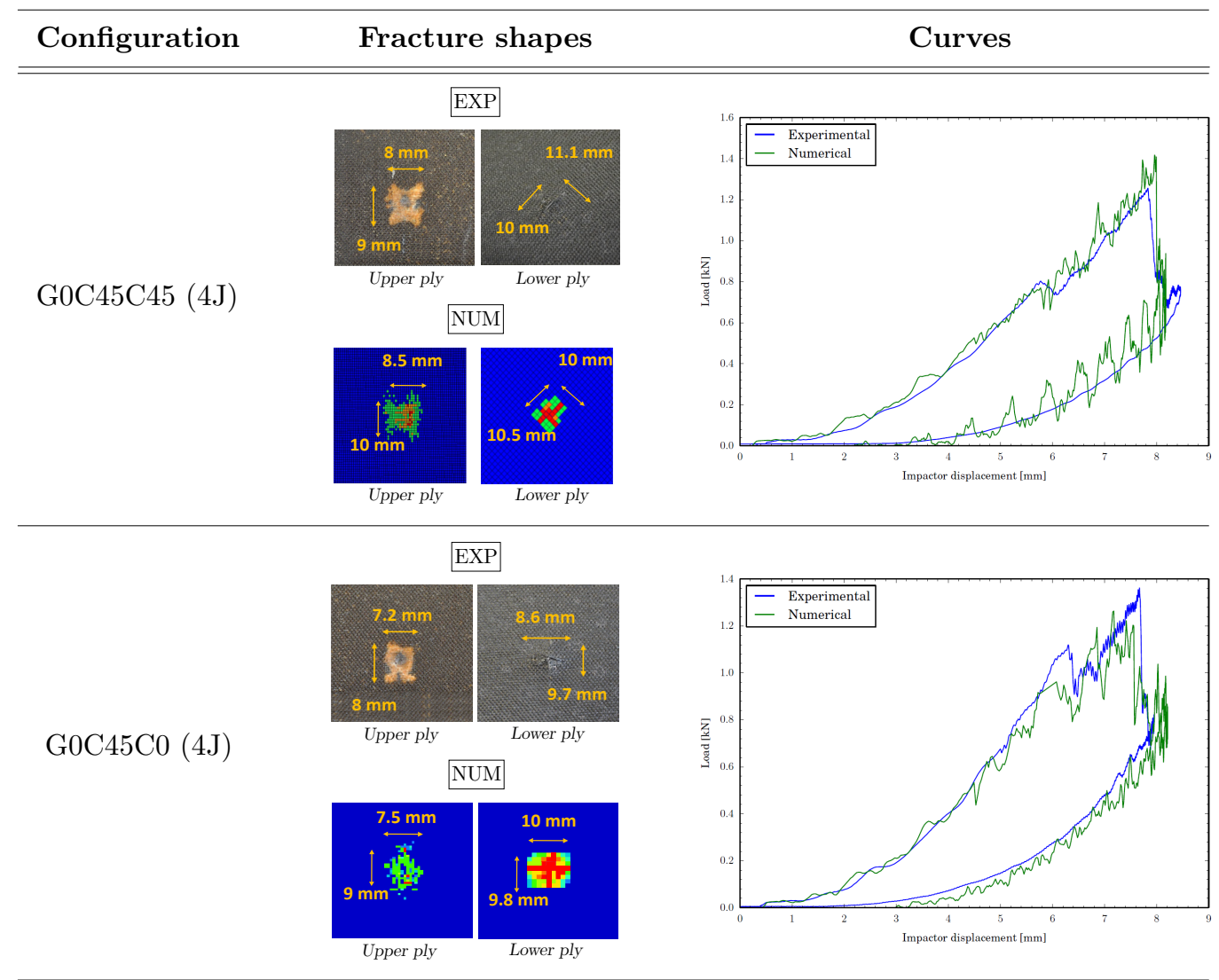

Figure 8: Drop weight impact results on hybrid laminates - Experimental and numerical comparaison 


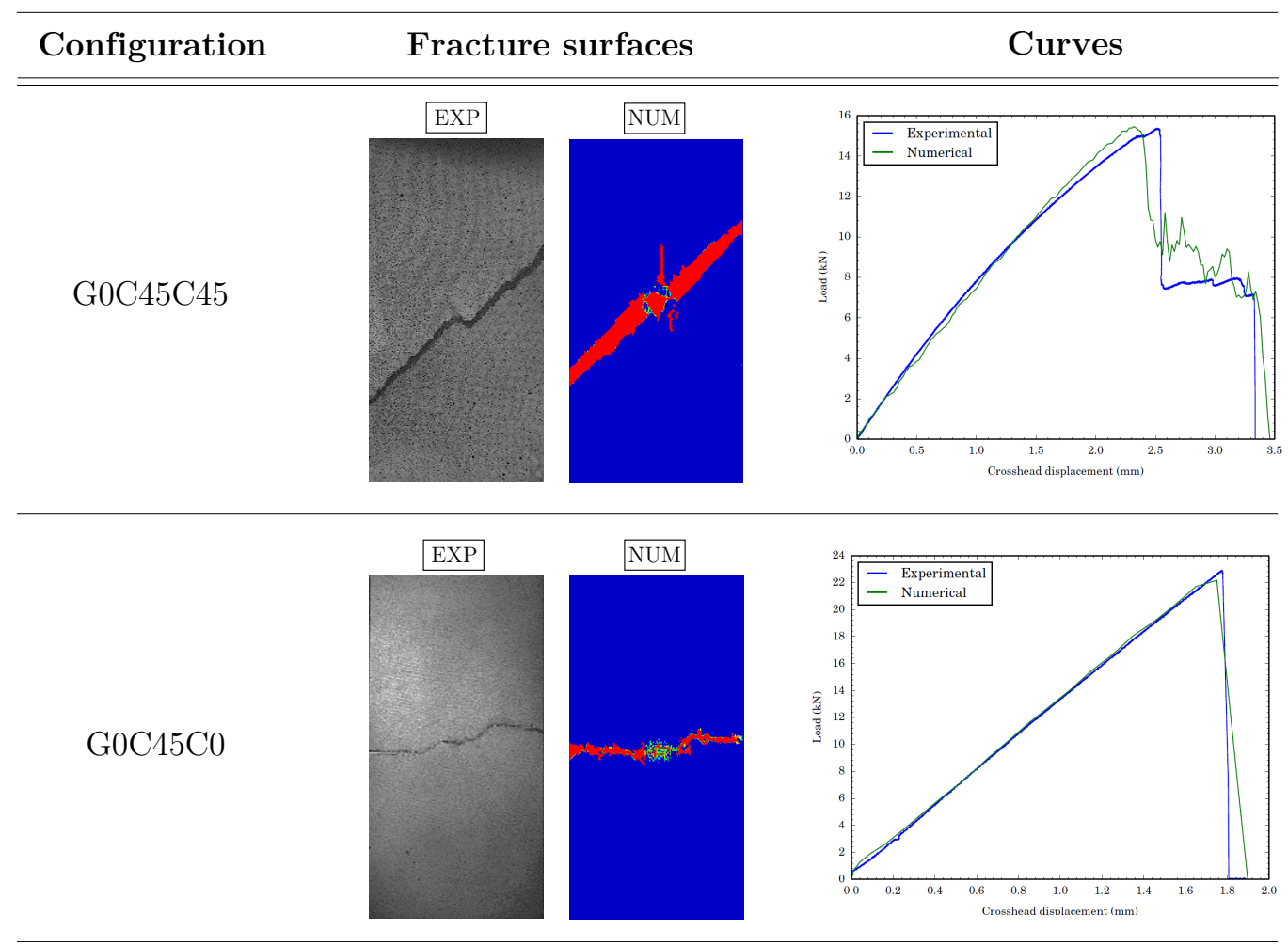

Figure 9: Fracture surfaces (identical for the upper and lower plies) and curves obtained after tensile tests on impacted hybrid laminates - Comparison between the experimental results 

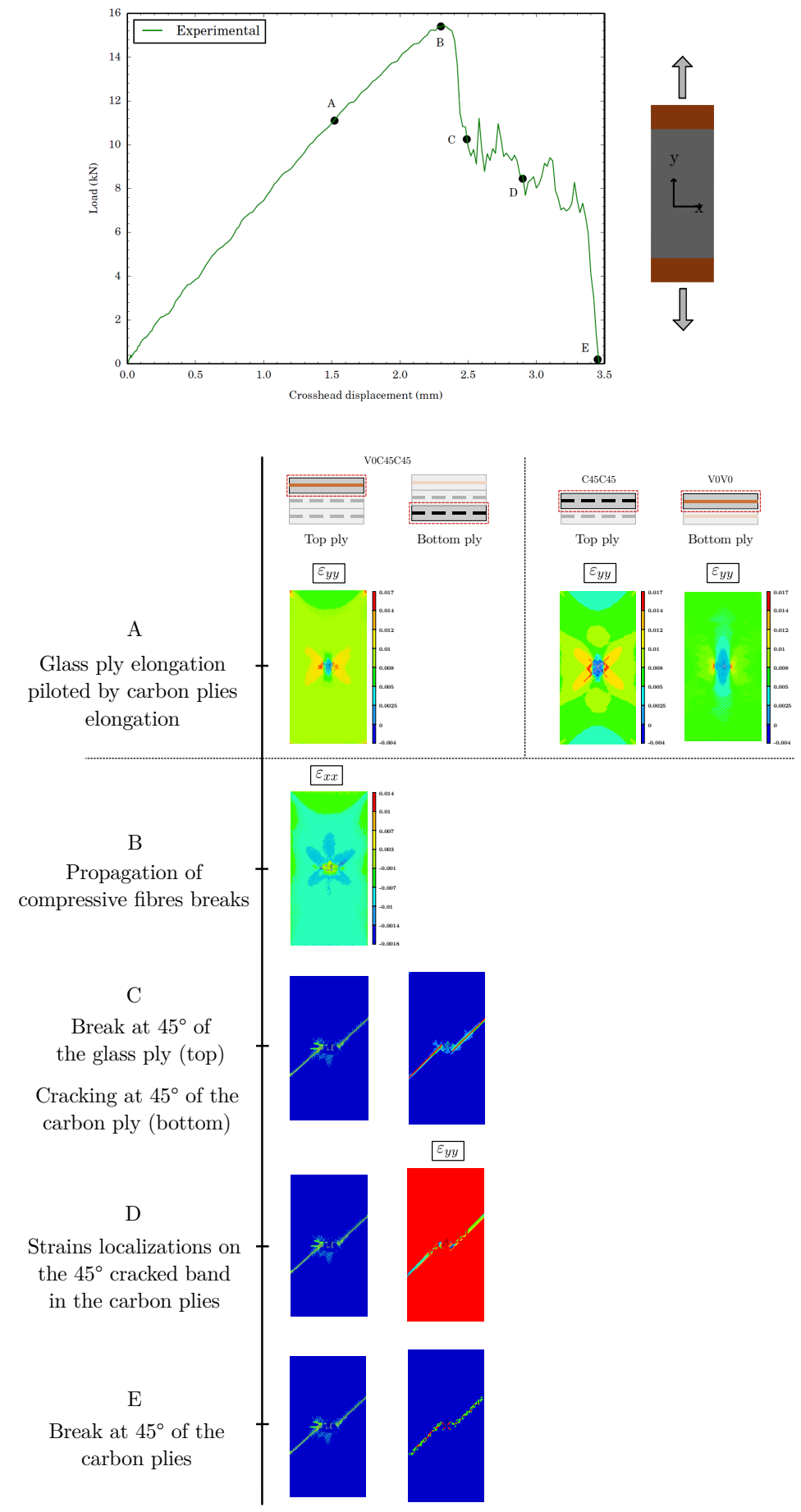

Figure 10: Scenario of damage propagation during a quasi-static tensile simulation on a $4 \mathrm{~J}$ impacted sample of G0C45C45 


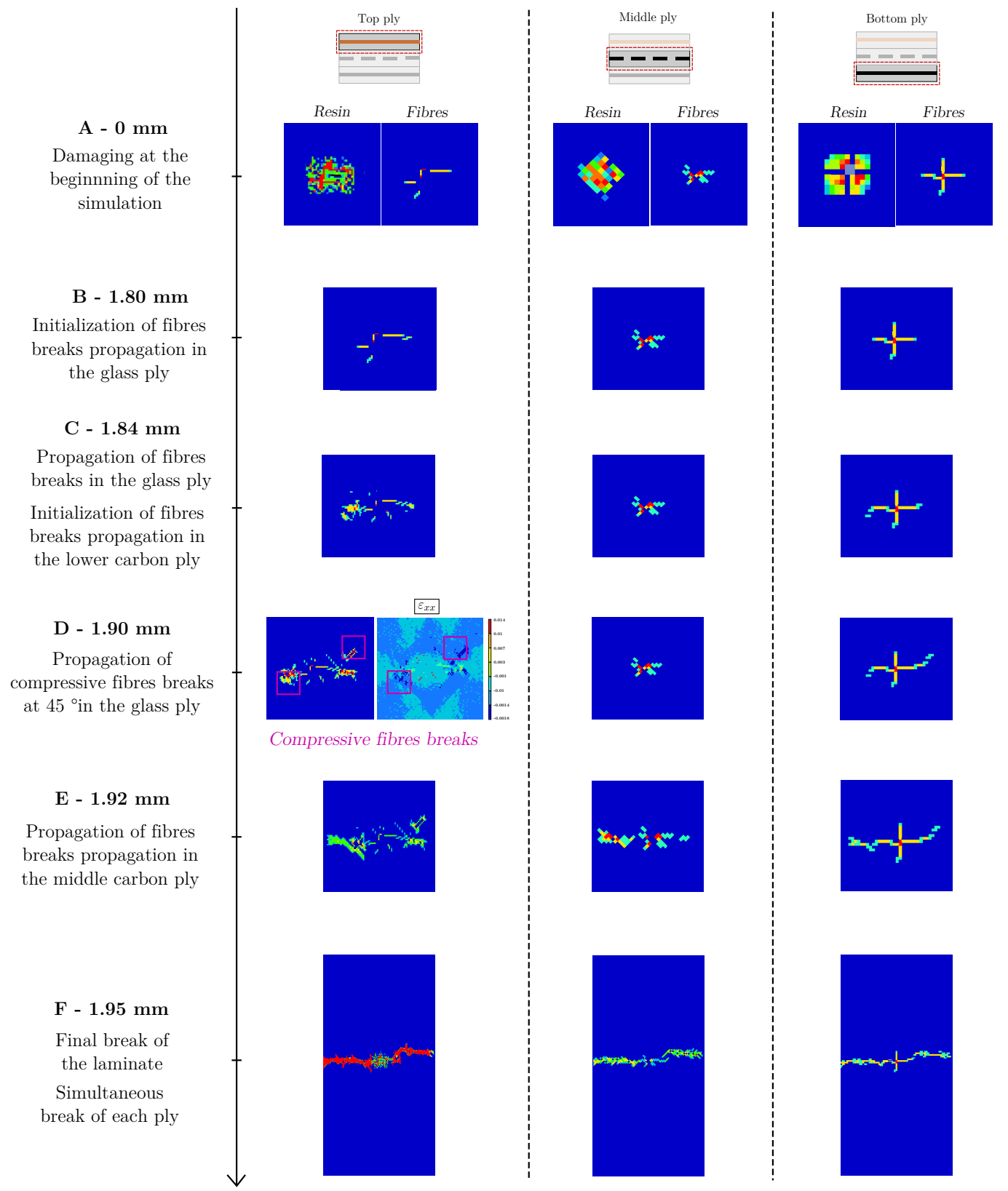

Figure 11: Scenario of damage propagation during a quasi-static tensile simulation on a $4 \mathrm{~J}$ impacted sample of $\mathrm{G} 0 \mathrm{C} 45 \mathrm{C} 0$ 


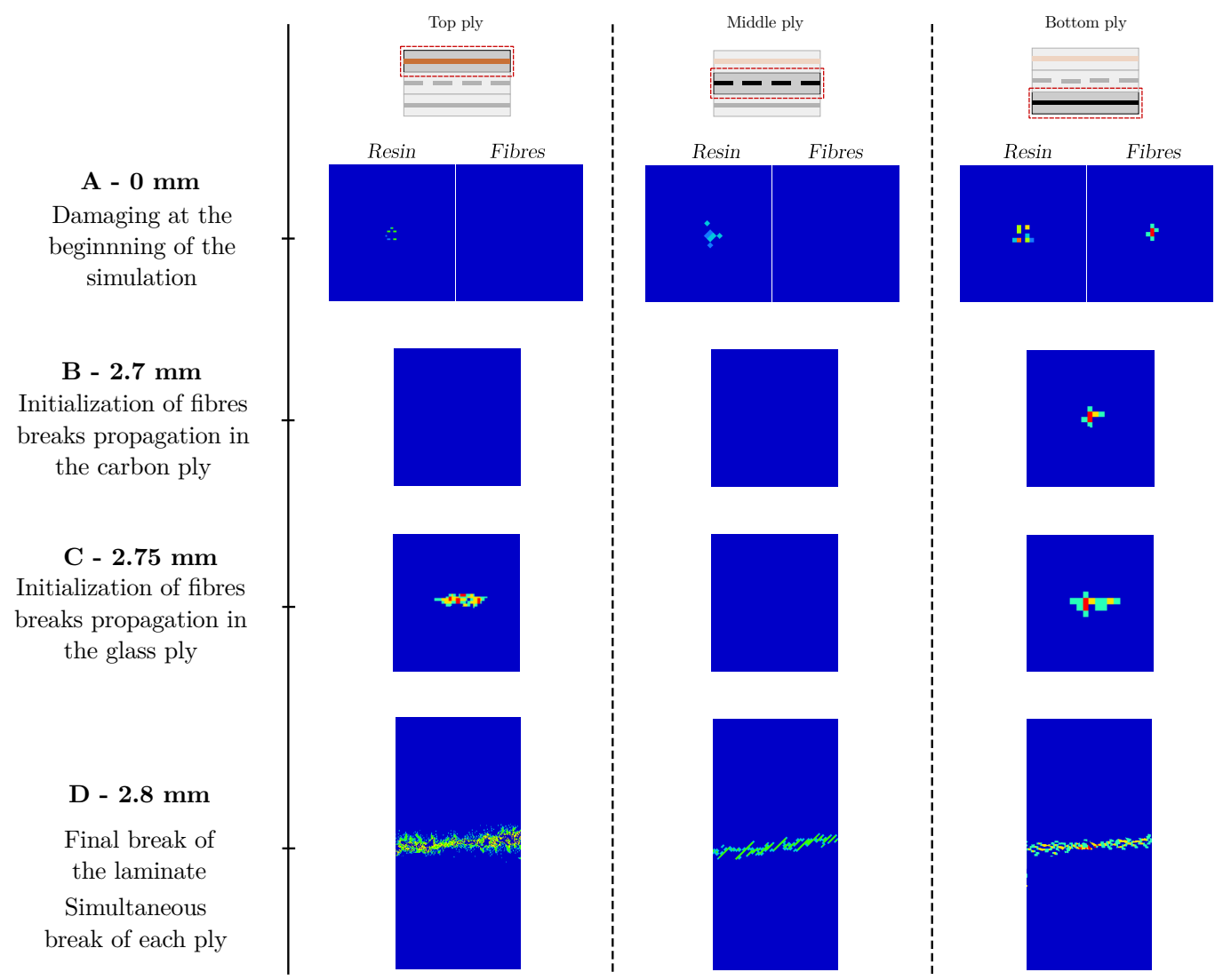

Figure 12: Scenario of damage propagation during a quasi-static tensile simulation on a $1 \mathrm{~J}$ impacted sample of $\mathrm{G} 0 \mathrm{C} 45 \mathrm{C} 0$ 


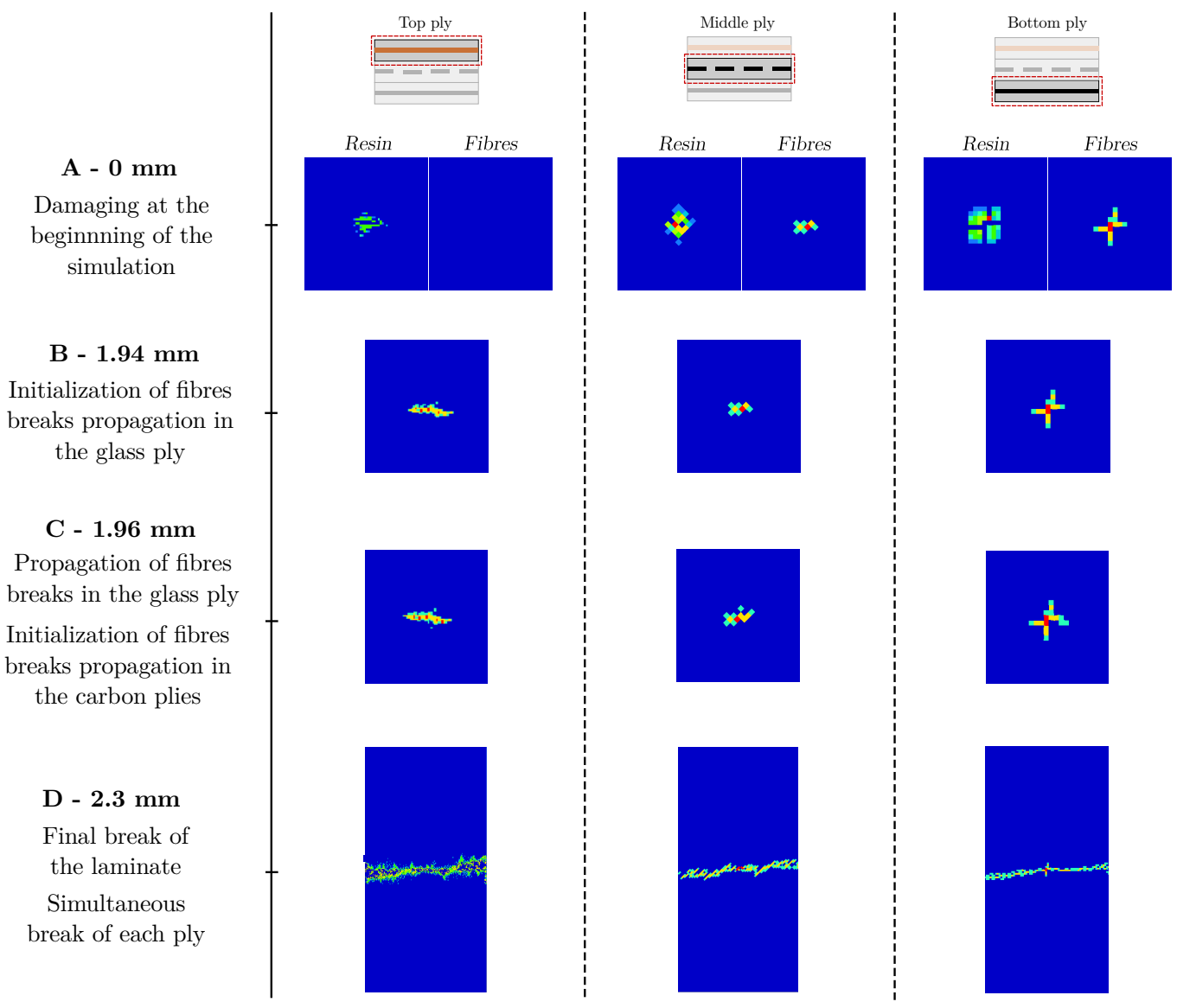

Figure 13: Scenario of damage propagation during a quasi-static tensile simulation on a $2.25 \mathrm{~J}$ impacted sample of $\mathrm{G} 0 \mathrm{C} 45 \mathrm{C} 0$ 


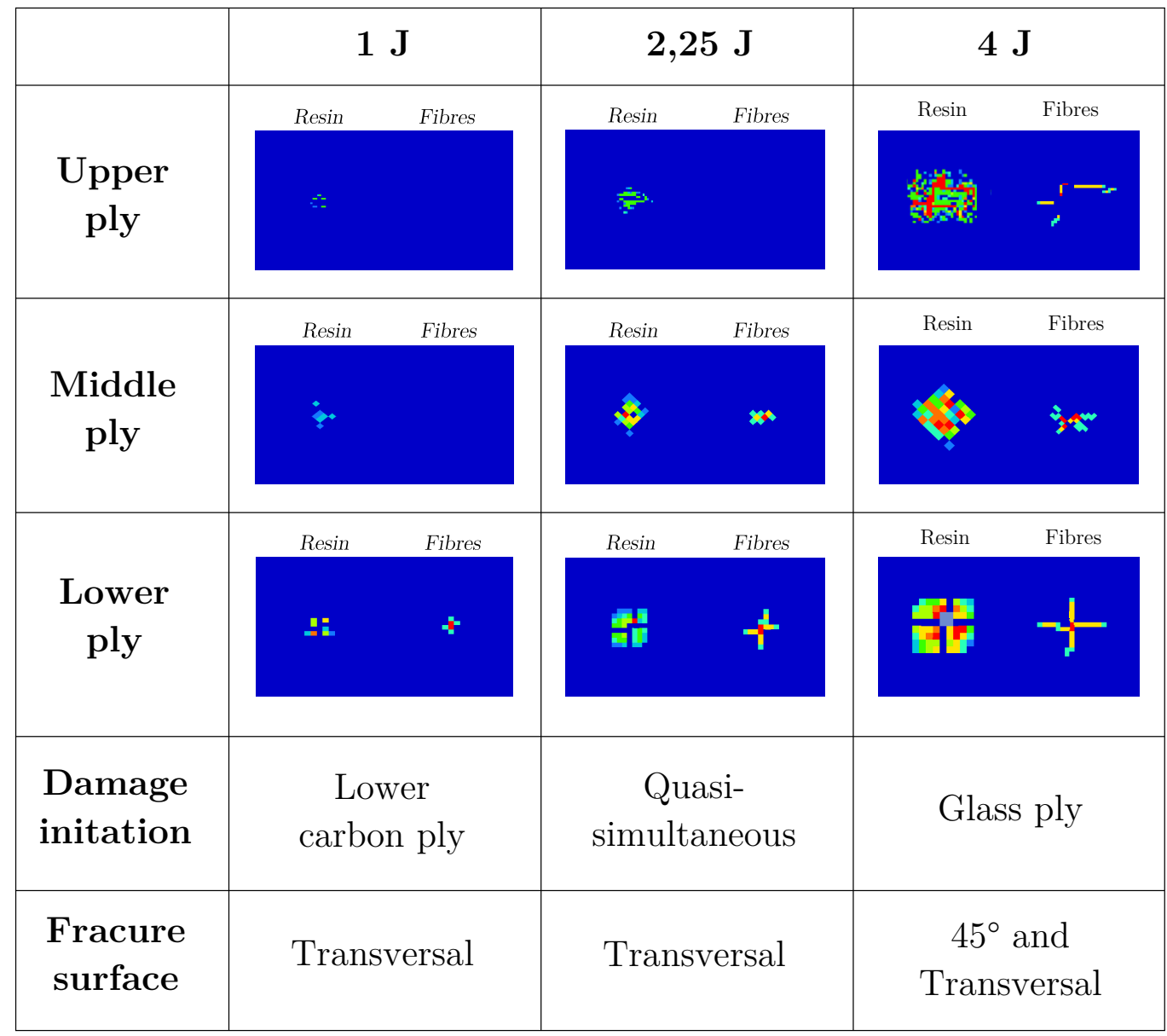

Figure 14: Damage initiation and fracture surfaces depending on the initial damage 


\begin{tabular}{|c|c|c|}
\hline Configuration & Lower ply & Upper ply \\
\hline C0C0 & Carbon $(0 / 90)^{\circ}$ & Carbon $(0 / 90)^{\circ}$ \\
C45C45 & Carbon $\pm 45^{\circ}$ & Carbon $\pm 45^{\circ}$ \\
C45C0 & Carbon $(0 / 90)^{\circ}$ & Carbon $\pm 45^{\circ}$ \\
G0G0 & Glass $(0 / 90)^{\circ}$ & Glass $(0 / 90)^{\circ}$ \\
\hline
\end{tabular}

Table 1: Configurations for single-material laminates

\begin{tabular}{|c|c|c|c|}
\hline Configuration & Lower ply & Middle ply & Upper ply \\
\hline G0C45C45 & Glass $(0 / 90)^{\circ}$ & Carbon $\pm 45^{\circ}$ & Carbon $\pm 45^{\circ}$ \\
G0C45C0 & Glass $(0 / 90)^{\circ}$ & Carbon $\pm 45^{\circ}$ & Carbon $(0 / 90)^{\circ}$ \\
\hline
\end{tabular}

Table 2: Configurations for hybrid laminates

\begin{tabular}{|c|c|}
\hline Pseudo-plasticity & $G_{12}^{0}, \tau_{0}, K_{\text {plas }}, \beta$ \\
\hline Damaging & $d_{12 a}^{\max }, Y_{0}, Y_{c}, Y_{0 b i s}, Y_{c b i s}, \phi_{\max }$ \\
\hline
\end{tabular}

Table 3: Parameters to identify for the damaging pseudo-plastic law

\begin{tabular}{|c|c|c|}
\hline Configuration & Initial velocity & Energy of impact \\
\hline C0C0 \& C45C45 \& C45C0 & & \\
G0G0 & $2 \mathrm{~m} / \mathrm{s}$ & $4 \mathrm{~J}$ \\
G0C45C45 & & \\
\hline & $1 \mathrm{~m} / \mathrm{s}$ & $1 \mathrm{~J}$ \\
G0C45C0 & $1.5 \mathrm{~m} / \mathrm{s}$ & $2.25 \mathrm{~J}$ \\
& $2 \mathrm{~m} / \mathrm{s}$ & $4 \mathrm{~J}$ \\
\hline
\end{tabular}

Table 4: Different energies of impact numerically tested 